\title{
DERECHO DE PROPIEDAD PRIVADA, BIEN COMUN Y PRINCIPIO DE SUBSIDIARIDAD
}

\author{
HECTOR RIESLE \\ Profesor de Introducción al Derecho
}

\section{Introducción}

Para estudiar las relaciones existentes entre el derecho de propiedad privada y el bien común, conviene aclarar previamente el concepto de éste.

El concepto de bien común es un concepto análogo con analogía de atribución, lo que equivale a decir que existe un bien común por esencia, o analogado principal, y que los otros bienes comunes o analogados inferiores tienen razón de: bien común sólo en cuanto participan o se refieren a aquel que lo es por esencia.

El bien común es la causa final de la sociedad lo que significa que es su razón de ser, la referencia que da valor y sentido a la existencia de ésta. Resulta evidente que sus contenidos concretos variarán según la sociedad de que se trate, pero todos contendrán en la razón análoga de bien común. Por otra parte, estos contenidos concretos, en cualquier tipo de sociedad de que se trate, y justamente por la necesaria referencia de cualquier bien común al bien común por esencia, deben respetar y realizar aquello que es intrínsecamente bueno para el hombre o, lo que es lo mismo, lo dispuesto por la ley divina y la ley natural.

Existen pues distintos tipos de bienes comunes concretos, pero análogamente semejantes y unos subordinados a otros en la medida de su mayor o menor proximidad al bien común por esencia.

Por todo lo dicho nuestro método aparece claro. Deberemos, en primer lugar, estudiar el concepto y contenidos esenciales del bien común análogamente concebido, aplicable a toda sociedad. Luego nos ocuparemos de la debida referencia de los analogados inferiores al bien común por esencia, y finalmente estudiaremos las relaciones entre el bien común y el derecho de propiedad privada.

\section{Apariencia y realidad de bien común}

Respecto al primer punto conviene puntualizar previamente que existen dos profundidades en el análisis del bien común como concepto análogo. Exteriormente considerado, aparece como bien común todo fin que un grupo de hombres, más o menos permanentemente asociados se proponga, y para cuyos efectos se fije. 
una determinada conducta. Así, podría hablarse de que el bien común de una banda de malhechores es obtener botín.

Pero tal visión es engañosa, pues el bien común no depende únicamente de lo que aparece claro como bueno, ni sólo de lo apetecido por los miembros de la sociedad sino de la naturaleza de las cosas. Pero que lo que aparece como bien común de una sociedad lo sea real, objetiva y entitativamente es necesario que tenga razón de bien común o, lo que es lo mismo, que participe y se oriente hacia el bien común por esencia.

\section{Concepto análogo de bien común}

Hay sociedad toda vez que existe un grupo de hombres que se vinculan unos a otros en forma más o menos permanente para alcanzar un fin determinado, para cuyo objeto se imponen una cierta conducta. Es evidente que si estos hombres se asocian y se someten a una cierta norma de conducta, es porque aspiran a alcanzar un bien determinado. Este bien interesa a todos y a cada uno de los miembros del grupo, es común a todos ellos y por eso se llama bien común. Interesa recalcar que es un bien de los miembros, y no un bien de la sociedad en cuanto tal. Precisamente es este bien de los miembros la justificación de la sociedad, en cuanto ella es necesaria para su obtención plena. Si los individuos pudieran alcanzarlo cada uno independientemente, la sociedad no tendría razón de ser. Esto es lo que expresa la genial definición de Vitoria, al decir que el bien común es el bien de los individuos conseguido en comunidad.

La sociedad, pues, está para los individuos y no éstos para ella. Esta relación de dependencia se explica pues la sociedad no es un ser substancial sino moral, que recibe la existencia de una determinación accidental de los seres substanciales -hombres-que la componen. Y a la prioridad en el ser corresponde prioridad en el fin, por lo que la sociedad aparece destinada a perfeccionar en algún sentido la vida de los hombres que la componen. En esta perfección consiste el bien común. Pero no es fin inmediato de toda sociedad el bien total del hombre, sino cada una persigue el bien que corresponde a su naturaleza y la especifica. Debiendo, eso sí, en cuanto su fin tenga razón de medio respecto a otro fin más elevado, subordinarse a él, lo que implica subordinarse en este respecto a la sociedad que lo persiga, si hay identidad material (si ambas tienen como eausa material a unos mismos hombres). Esta es la base ontológica del principio de subsidiaridad, según el cual las sociedades se subordinan según la jerarquía de los fines, pero manteniéndose las inferiores con sus competencias propias en cuanto subsistan los fines que las especifican.

\section{Bien común y bien social o comunitario}

Según hemos visto, el bien común es un bien de los individuos, con lo que 
aparece claro que entre bien común y bien individual no existe oposición metafísica, sino más bien una correlación armónica. Pero el hecho de que sea un bien de los individuos no quiere decir que se identifique con todo bien de éstos. Hacer del bien común el bien de la sociedad en cuanto tal es el error del socialismo. Considerarlo sinónimo de suma de bienes individuales es el error del liberalismo. El bien común es bien de los individuos, pero se distingue del bien exclusivamente individual por una diferencia que no es simplemente cuantitativa, en cuanto a ser bien de la mayoría, sino cualitativa, en cuanto sólo puede ser obtenido en comunidad y conviene, de algún modo, a todos.

Como existen muchos bienes individuales que no son bien común, puede darse el caso de una oposición circunstancial entre el bien común y un bien de al. gún individuo (suponiendo que este último bien tenga verdaderamente razón de tal, y no sea una mera apariencia). Pese a este conflicto, el bien común sigue siendo bien de ese individuo. Esta posible contradicción resulta muy ilustrativa para apreciar la diferencia cualitativa que existe entre ambas clases de bienes. Supongamos que un particular ve extinguida por prescripción de una acción de la que disponía contra un tercero. Sin duda, aparece como bien exclusivamente individual de este hombre la posibilidad de seguir ejerciendo su acción. Pero la necesidad de seguridad jurídica, requisito esencial del bien común, impone la norma contraria, es decir, la extinción de ésta por la prescripción. No hay en este caso un conflicto entre la conveniencia de uno y la conveniencia de los demás, sino entre un bien de un individuo y un bien común a todos, inclusive al mismo titular del derecho contrapuesto, pues la seguridad jurídica sigue siendo un bien importantísimo para ese individuo, y condición necesaria para el ejercicio pacífico de todos sus derechos.

\section{Bien común y bien social comunitario}

El bien común no equivale a bien social o comunitario, pues este último se refiere a la sociedad en cuanto tal, mientras que el primero se refiere a los individuos en cuanto miembros de la sociedad. Un ejemplo puede ilustrar la diferencia: se puede considerar como bien comunitario, respecto a la sociedad política, un aumento considerable de su potencia militar, pues la robustece frente a los otros Fistados. Pero por ser bien comunitario no es necesariamente bien común. Jo será si ese aumento de poderío es realmente necesario para salvaguardar la justicia, paz y seguridad entre los ciudadanos y la independencia de la Nación. Por el contrario, si sólo se tratara de un afán expansionista motivado por las aspiraciones del dueño del poder, y se hiciera a costa de innecesarios sacrificios de los súbditos, seria atentatorio contra el bien común, aunque hiciera a la sociedad de que se trate más poderosa que las demás. Podría haber bien social o comunitario, pero no bien común.

En la sociedad política el bien social o comunitario, en lo que al aspecto 
económico se refiere, es el bien fiscal. Todo mayor ingreso en arcas fiscales, todo nuevo tributo, es bien fiscal. Pero no todo bien fiscal tiene razón de bien común. Antes bien, una tributación excesiva que olvide el principio de subsidiaridad, lesione derechos naturales como los de propiedad o herencia, o recargue de tal manera las costas judiciales que imposibilite a la población el acceso a los tribunales, serían gravemente atentatorios al bien común.

\section{Los contenidos del bien común}

a) Bien común primario, específico o primordialmente perseguido :

Hemos visto que el bien común es el bien de los individuos conseguido en comunidad, el fin que la sociedad persigue, su causa final.

Así, al comenzar nuestro análisis de los contenidos del concepto de bien común, encontramos en primer lugar al objeto perseguido, al fin que especifica a la sociedad, lo que se pretende primordialmente alcanzar. Dicho fin es, pues, la primera forma de bien común, y queda determinado por la naturaleza misma de la sociedad (sobrenatural o de derecho divino, como la Iglesia; sociedades naturales, como la familia y el Estado; y finalmente, sociedades de simple derecho positivo. En el caso de la Iglesia y de las sociedades naturales el fin queda completamente determinado por su naturaleza, mientras que en las de derecho positivo queda fijado por el acto voluntario o constitutivo, sea éste una decisión de la autoridad o un contrato).

Podemos, pues, llamar a esta primera forma que nos ha mostrado el análisis, bien común primario, específico o primordialmente perseguido.

Fste bien común primario o específico puede, según los casos pertenecer tanto a la categoría de lo agible o moral cuanto a la de lo factible. Así, en el caso del Estado, el bien común específico es la buena vida virtuosa entre sus miembros, la vida de virtud en común, por lo que se inscribe fundamentalmente en el campo de lo agible. A la inversa, en una sociedad comercial el bien común primordial se inscribirá en la órbita de lo factible, como será la obtención de utilidades.

b) Bien común agible, necesario y subordinado:

Mas, para conseguir el bien común primario y específico, es necesario un cierto orden y coordinación en el actuar de los miembros que los oriente y disponga para alcanzarlo útilmente. Y en cuanto este orden y coordinación en el actuar es necesario para alcanzar el fin primordialmente propuesto, es un bien para todos los miembros de la sociedad, un bien común, pero que no tiene esta calidad por sí mismo, sino participada del bien común específico o primario, en cuanto es medio necesario para su obtención.

Así, este orden y coordinación en el actuar de los miembros constituye una 
categoría de bien común que podriamos caracterizar como secundaria y subordina$\mathrm{da}$, pero desde todo punto de vista necesaria y que se inscribe plenamente en el campo de lo agible. Se trata pues de una categoría esencialmente moral, que por lo tanto debe respetar siempre los dictados de la ley moral general, dentro de cuyos cauces debe operar, ya que de lo contrario por alcanzar el fin inmediato se estaría perdiendo el último, que es el que posee por sí mismo razón de bien. El contenido concreto de esta forma de bien común quedará fijado en cada caso genéricamente por la ley moral, y especificamente por las disposiciones prudenciales tendientes a alcanzar de modo eficaz el bien común primario que a esa sociedad concreta corresponda.

c) Contenidos concretos contingentes:

Para realizar adecuadamente el contenido del bien común en cada sociedad concreta se requieren una cantidad de condiciones, que variarán en cada caso según la naturaleza de la sociedad y las circunstancias en que deba desenvolverse.

Nos encontramos aquí ante un mayor grado de concreción. Las condiciones que se derivan de la misma naturaleza de la sociedad de que se trate aparecen como contingentes si se las compara con los contenidos esencialmente necesarios que venimos de estudiar. Pero se enraizan en el mismo ser concreto, aunque sea por lo que en él es más accidental y particularizado, lo que las distingue claramente de las condiciones que se derivan de lo meramente ocacional y circunstancial.

De más está decir que en cada sociedad deben concurrir todos estos contenidos y condiciones para alcanzar el bien común que concretamente le corresponde. A nuestra inteligencia corresponde la facultad de distinguir los distintos elementos que se dan en el ser, pero no la de separarlos efectivamente unos de otros.

\section{Bien común, autoridad y sociedad}

Las relaciones entre el bien común, causa final de la sociedad, y la autoridad, causa formal de ésta, son muy estrechas: por una parte la autoridad impone a los miembros la conducta adecuada para la obtención del fin, con lo que se fija el contenido concreto de la especie subordinada agible necesaria de bien común. Por otra, es la que a través de tal función orienta a la sociedad a la consecución del bien originalmente perseguido. Pero, a su vez, la autoridad sólo tiene razón de ser en cuanto su gestión obtenga las condiciones adecuadas para alcanzar el fin primordialmente propuesto, con lo que el bien común, en cuanto concretamente alcanzado en forma progresiva, opera como causa justificativa y legítimamente de la autoridad, por Io que de algún modo opera como causa formal de la sociedad.

Bien común y sociedad política

Hemos dicho que el bien común específico de la sociedad política ex de na- 
turaleza esencialmente agible, moral: la buena vida virtuosa, la vida de virtud en común, o, dicho de otro modo, la virtud practicada en comunidad. Esta definición del Angel de las Escuelas (De regimine principum, Lib. I, cap. XIV) se inscribe, como la especie en el género, en la anterior definición de Vitoria del bien común en su acepción más análoga. Pues si no hay en el orden natural mayor bien para el hombre en esta vida que la práctica de la virtud, el bien de los individuos conseguido en comunidad específico de la sociedad natural más alta será necesariamente la virtud conseguida en común o, lo que es lo mismo, la práctica de ella por la comunidad.

\section{Bien común por esencia}

El bien común por esencia debe ser común a todos los hombres y contener en sí mismo toda razón de bien, asi se identifica con el fin último del hombre, es decir, con Dios. Esto se ve más claro si pensamos que el bien común es causa final de toda ley. Y ésta, para ser ley, esto es, para dirigir y regular verdaderamente los actos humanos, debe ordenarse al fin último, pues de éste recibe, en definitiva, su razón de ser. Este fin último es Dios, que siendo causa universal, tanto eficiente como final, de todos los seres, y especialmente del hombre, es en sentido propio el bien común ${ }^{1}$. "Bien común por esencia, por ser la misma bondad subsistente; y fin universal por esencia, no finalizado ni finalizable por ningín otro fin. Es el primero y supremo analogado de la razón de bien común, a quien tanto la razón de bien como la razón de común y universal convienen primordialmente y en toda su plenitud y perfección" 2. Asi, el bien común de toda ley debe ser el fin último de la vida humana, el bien común perfecto ${ }^{3}$, es decir, la bienaventuranza. Y a este bien deben orientarse todos los demás bienes comunes, pues de él reciben su razón de bien.

Lo que Santo Tomás expresa así: "Por otra parte, en cualquier género de cosas, lo que es por antonomasia, es principio de todo lo demás, y todo lo demás se denomina por orden a ello, como el fuego, que es el sumo calor, es causa del calor en los cuerpos mixtos, los cuales tanto se denominan cálidos en cuanto participan del fuego. De donde se sigue que, constituyéndose la ley ante todo por orden al bien común, cualquier otro precepto sobre un objeto particular no tiene razón de ley sino en cuanto se ordena al bien común. Por tanto, toda ley se ordena al bien común" 4 ..

Y más adelante agrega: "Asi como en el orden especulativo nada se da por firmemente probado a no ser por una reducción a los primeros principios indemostr ables, así en el orden práctico nada establece la razón sino por orden al último fin, que es el bien común. Pero todo lo que de este modo establece la razón práctica, tiene carácter de ley" 5 .

El pensamiento de Santo Tomás a este respecto se puede resumir en tres afirmaciones: "10. La ley moral (es decir, de los actos humanos), mira primaria y 
formalmente al bien común por esencia, que es Dios, fin último y bien común perfecto de la vida humana.

" 20 . Las distintas especies o clases de leyes miran inmediatamente hacia sus respectivos fines o bienes comunes, distintos entre sí, pero subordinados y en relación necesaria al bien común por esencia o fin último.

“3o. Los bienes comunes derivados reciben su razón de bien común del bien común por esencia y, por consiguiente, las diversas leyes de los actos humanos reciben su género moral dentro de la razón misma de la ley en cuanto ordenadas, no siempre inmediata y explícitamente, a este último fin o bien común por esencia" 6 .

Bienes comunes derivados

Así, cada ley tiene por fin un bien común orientado hacia el fin último. A la ley divina corresponde la bienaventuranza sobrenatural, completada por la ley natural y a la ley humana positiva que es su derivación, la bienaventuranza natural.

La ley natural tiene por fin, pues, la bienaventuranza natural, bonum commune morale (q. 94 a. 3 ad 1), la perfección humana total respecto al último fin natural, que es el bien común de todos los hombres. Se adquiere por el ejercicio de todas las virtudes morales auxiliadas por todas las fuerzas naturales del hombre a ellas sometidas. En definitiva, la ley natural ordena y produce en concreto el orden de los actos humanos al orden moral, que es la parte más importante del orden universal regido por la ley eterna.

La ley humana es una derivación de la ley natural, sea a título de conclusión o simple determinación de sus preceptos. En consecuencia, tiene por fin la bienaventuranza natural, que no se puede alcanzar sin la sociedad humana regida por la ley positiva. Pero en definitiva el bien común de la sociedad civil es un bien común limitado a una sociedad concreta. con determinados miembros y ciertas características, y por ello mismo no agota el contenido de la bienaventuranza natural. Así, aun cuando él contiene y supone la mayor abundancia posible de bienes espirituales y materiales, consiste principalmente en la paz y tranquilidad públicas, la unión de los ciudadanos entre sí y con la autoridad que los gobierna. Esta paz y esta unión, que viene a ser formalmente el bien común inmanente a la sociedad política, son el objeto de la ley positiva, que a través de ellos órienta a sus miembros para que puedan alcanzar la felicidad terrena.

Finalmente, la bienaventuranza sobrenatural es el bien común de la ley divina positiva ${ }^{7}$.

De to visto se deduce con claridad que existe una jerarquía entre los bienes comunes, correspondiente a la jerarquía de las leyes. Ahora, entre la ley divina y la ley natural no puede haber contradicción, pues ello equivaldría a sostener una con- 
tradicción de Dios consigo mismo, lo que repugna a la razón. Ia ley humana, por su parte, tendrá razón de ley en la medida en que proceda de la ley natural.

Así lo expresa Pío XI, al decir: "Una y la misma es, efectivamente, la ley moral que nos manda buscar, así como directamente en la totalidad de nuestras acciones nuestro fin supremo y último, así también en cada uno de los órdenes particulares esos fines que entendemos que la naturaleza, o mejor dicho, el autor de la naturaleza, Dios, ha fijado a cada orden de cosas factibles, y someterlas subordinadamente a aquél. Obedeciendo fielmente esta ley, resultará que los fines particulares, tanto individuales como sociales, perseguidos por la economía, quedan perfectamente encuadrados en el orden total de los fines, y nosotros, ascendiendo a través de ellos como por grados, conseguiremos el fin último de todas las cosas, esto es, Dios, bien sumo e inexhausto de sí mismo y nuestro" 8 .

\section{Relaciones entre el bien común y el derecho de propiedad}

Cumple ahora ocuparnos de las relaciones que existen entre los distintos tipos de bienes comunes y el derecho natural de propiedad privada:

Desde un punto de vista general

En primer lugar, si el bien común es siempre perfección de la naturaleza, presupone que se respete ésta. La bienaventuranza, tanto natural como sobrenatural, son perfección de la naturaleza, y a ellas se orientan todas las leyes. Si el derecho de propiedad privada es, como hemos demostrado, un derecho natural, y la ley natural, ontológicamente, es la naturaleza, suprimir o violar tal derecho es atentar contra la naturaleza humana, es decir, imposibilitar radicalmente la obtención plena de cualquier bien común. "Pues si los ciudadanos, si las familias, hechos partícipes de la convivencia y sociedad humanas, encontraran en los poderes públicos perjuicio en vez de ayuda, un cercenamiento de sus derechos más bien que una tutela de los mismos, la sociedad sería, más que deseable, digna de repulsa" 9 .

Esto, que vale como principio general, lo estudiaremos con más detalle respecto a cada especie de bien común.

\section{Respecto al bien común por esencia}

1.- En cuanto al amor a Dios: el primer deber del hombre, el mayor mandamiento, es amar a Dios. "El conocimiento y el amor de la Ley son inseparables del conocimiento y del amor de Dios. Pues la Ley es de algún modo el espejo de la santidad divina. $Y$ esto, que se puede decir de cada uno de sus preceptos, es verdad principalmente cuando ella es considerada en su conjunto. Renunciar a enseñar los dos 
preceptos del Decálogo que fundamentan la propiedad privada importaría presentar una imagen desfigurada de ese conjunto, y por tanto del propio Dios. Ahora, donde las almas tienen una idea desfigurada respecto de Dios, ellas se forman segín un modelo errado, lo que es incompatible con la verdadera santificación" 10 .

2.- Respecto del desarrollo de la virtud cardinal de la justicia, la supresión de la propiedad privada tiene gravísimas consecuencias: "Las virtudes cardinales son, como dice el nombre, goznes sobre los que se apoya toda la santidad. Para que el alma se santifique debe conocerlas rectamente, amarlas sinceramente y practicarlas genuinamente.

"Acontece que toda la noción de justicia se funda en el principio de que cada hombre, su prójimo individualmente considerado y la sociedad humana, son respectivamente titulares de derechos, a los que corresponden, naturalmente, deberes. En otros términos, la noción del "mío" y del "tuyo" está en la base más elemental del concepto de justicia.

"Ahora, precisamente esa noción del "mío" y del "tuyo" en materia económica, conduce directa e inevitablemente al principio de la propiedad privada.

"De donde, sin el conocimiento recto de la legitimidad y de la extensión -como además de la limitación- de la propiedad privada, no hay conocimiento recto de lo que sea la virtud cardinal de la justicia.

"Y sin ese conocimiento no son posibles un verdadero amor, ni una verdadera práctica de la justicia: en suma, no es posible la santificación" 11 .

3.- Desde un punto de vista más genérico, del pleno desenvolvimiento de las facultades del alma y de su santificación: "La explanación de este argumento presupone como asentado que la recta formación de la inteligencia y de la voluntad, bajo varios aspectos sirve de molde para favorecer la santificación, y bajo otros, hasta se identifica con ella. Y que, "a contrario sensu", todo cuanto perjudica a la recta formación de la inteligencia y de la voluntad, bajo varios aspectos es incompatible con la santificación.

"Vamos a mostrar que una sociedad en que no exista la propiedad privada es gravemente opuesta al recto desenvolvimiento de las facultades del alma, especialmente de la voluntad. Por lo que, de suyo, es incompatible con la santificación de los hombres.

"De paso nos hemos de referir también al perjuicio que, por análogas ra . zones, la comunidad de bienes acarrea para la cultura. Digo hemos, porque el verdadero desenvolvimiento cultural es, no sólo factor propicio a la santificación de los pueblos, sino también fruto de esa santificación. Por lo que la recta vida cultural tiene íntimo nexo con nuestro tema.

“Abordemos el asunto poniendo en evidencia un punto esencial, frecuente- 
mente ovidado por los que tratan de la institución de la propiedad privada: ésta es necesaria al equilibrio y a la santificación del hombre.

"Para justificar esta tesis cumple recordar, preliminarmente, que los documentos pontificios, cuando discurren sobre el capital, el trabajo y la cuestión social. no dejan la menor duda en cuanto al hecho de que la propiedad particular no sólo es legítima, sino aún indispensable al bien privado y al bien común, y esto no en lo que se refiere tanto a los intereses materiales del hombre, cuanto a los de su alma.

"Es bien cierto que esos mismos documentos papales se han levantado vehementemente contra los numerosos excesos y abusos que, principalmente a partir del sigho XIX, han ocurrido en materia de propiedad privada. El hecho, sin embargo, de ser muy reprobables y dañosos los abusos que los hombres hagan de una institución, absolutamente no quiere decir que por esto ella no sea intrínsecamente excelente. Antes, debe tenderse, las más de las veces, a pensar lo contrario: "corruptio optimi pessima", lo pésimo es, tal vez, la corrupción de aquello que en sí mismo es optimo. Nada tan sagrado y santo, en sí mismo y desde todos los puntos de vista, como el sacerdocio. Nada peor que la corrupción de él. Y por esto mismo se comprende que la Santa Sede, tan severa contra los abusos de la propiedad privada, sea aín más severa cuando reprime los abusos del sacerdocio.

"Múltiples son los motivos por los cuales la institución de la propiedad privada es indispensable a los individuos, a las familias y a los pueblos. Sobrepasaría los límites del presente trabajo una exposición completa de esos motivos. Atengámonos a la explanación de aquel que más directamente importa a nuestro tema: como hace poco afirmamos, tal institución es necesaria para el equilibrio y la santificación del hombre.

"Siendo naturalmente dotado de inteligencia y voluntad, el hombre tiende por sus propias facultades espirituales a proveer todo cuanto es necesario para su bien. De donde le viene el derecho de procurar por sí mismo las cosas que precisa y de ellas apropiarse cuando no tienen dueño. De ahí le viene igualmente el derecho de proveer de modo estable a sus necesidades del día de mañana, apropiándose del suelo, cultivándolo y produciendo, para ese cultivo, sus instrumentos de trabajo. En suma, es porque tiene alma que el hombre tiende incontestablemente a ser propietario.

"Y es en esto, dicen León XIII y San Pio X, que su posición frente a los bie nes materiales lo distingue de los animales irracionales: "IV - El hombre tiene sobre los bienes de la tierra no sólo el simple uso, como los brutos, sino también el derecho de propiedad estable, tanto respecto de las cosas que se consumen por el uso, como de las que el uso no consume. (Enc. Rerum Novarum)", (San Pío X, Motu Proprio sobre la Acción Popular Católica, de 18 de diciembre de 1903. A.A.S., vol. 36, p. 341-34.3). 
"Ahora, como el dirigir su propio destino y proveer a su propia subsistencia es objeto próximo, necesario y constante del ejercicio de la inteligencia y de la voluntad, y la propiedad es medio normal para que el hombre esté y se sienta seguro de su porvenir y señor de sí, acontece que abolir la propiedad privada, y en consecuencia entregar al individuo como hormiga inerme a la dirección del Estado, es privar a su mente de algunas de las condiciones básicas de su normal funcionamiento. Es llevar a la atrofia por el inejercicio a las facultades de su alma, es, en suma, deformarlo profundamente. De ahí, en gran parte, la tristeza que caracteriza a los pueblos sujetos al comunismo, bien como el tedio, las neurosis y los suicidios cada vez más frecuentes en ciertos países largamente socialistas del Occidente.

"Es bien sabido, en efecto, que las facultades del alma que no se ejercitan tienden a trofiarse. Por el contrario, el ejercicio adecuado puede desarrollarse, a veces, hasta prodigiosamente. En esto se fundan gran número de prácticas didácticas y ascéticas aprobadas por los mejores doctrinarios, y consagrados por la experiencia.

"Siendo la santidad la perfección del alma, bien se comprende de cuánta importancia es, para la salvación de los hombres, lo que de ahí se concluye. La condición de propietario, de si, crea circunstancias altamente propicias para el recto y virtuoso ejercicio de las facultades del alma. Sin que se acepte el ideal utópico de una sociedad en que cada individuo, sin excepción, sea propietario, o en la cual no hay a patrimonios desiguales, grandes, medios y pequeños, cumple afirmar que la difusión tan amplia como sea posible de la propiedad favorece el bien espiritual, y obviamente también el cultural, sea de los individuos, sea de las familias, sea de la sociedad. En sentido opuesto, la proletarización crea condiciones altamente desfavorables para la salvación, la santificación y la formación cultural de los pueblos, familias e individuos" 12 .

No se diga que, según los argumentos expuestos, los no propietarios quedarían sin posibilidad de santificación, o que el derecho de propiedad sería la causa de la elevación moral y cultural de los pueblos. La primera objeción se refuta diciendo que siendo elevado el número de personas que aprovechan adecuadamente de los beneficios morales y culturales que les confiere la condición de propietarios, resulta un ambiente social elevado en el que por la natural comunicación de las almas son favorecidos los no propietarios. De donde se deduce que la condición de no propietario en un régimen en que se reconozca la propiedad privada, es muy superior a la de quien vive en un régimen donde tal propiedad no existe. Respecto a la segunda objeción, no se puede afirmar que la propiedad privada sea la causa de la elevación moral y cultural de los pueblos, pues ello supondría poner lo sobrenatural en dependencia de la economía, pero sí que es un factor muy importante para el bien de las almas, impuesto por la naturaleza, y en consecuencia, un requisito importantísimo para toda auténtica elevación moral o florecimiento cultural ${ }^{13}$. 
Derecho de propiedad privada y bienes comunes derivados.

Dada la jerarquía de los fines que hemos analizado, el bien común de la sociedad civil se ordena al bien común por esencia, a la bienaventuranza, ya "que la felicidad verdadera y perfecta $y$, por consiguiente, eterna se nos ofrece a nosotros en el cielo como premio de una vida bien vivida; que a ésta debe tender todo cuanto hagamos" ${ }^{14}$, de lo que resulta que el bien común temporal, teniendo su órbita de competencia propia, se ordena al bien espiritual, a la bienaventuranza. Así, realmente, el fin de la sociedad y del Estado es la vida de virtud en común ${ }^{15} .{ }^{16}$, y hemos visto cuán perjudicial para la práctica de la virtud es la supresión de la propiedad privada. Pues. "de la forma dada a la sociedad, conforme o no a las leyes divinas, depende y ee insinúa también el bien o el mal en las almas, es decir, el que los hombres, llamados todos a ser vivificados por la gracia de Jesucristo, en los trances del curso de la vida terrena respiren el sano y vital aliento de la verdad y de la virtud moral o el bacilo morboso y muchas veces mortal del error y de la depravación" 17. "Defendiendo, por consiguiente, el principio de la propiedad privada, la Iglesia persigue un alto fin ético-social. No pretende ya sostener pura y simplemente el actual estado de cosas, como si en ello viera la expresión de la voluntad divina, ni proteger por principio al rico y al plutócrata contra el poble y no habiente, ;todo lo contrario! Desde los orígenes ella ha sido la defensora del débil oprimido contra la tiranía del poderoso y ha patrocinado siempre las justas reinvindicaciones de todos los grupos de los trabajadores contra toda iniquidad. Ahora, que la Iglesia mira sobre todo a lograr que la institución de la propiedad privada sea efectivamente tal cual debe ser conforme a los designios de la sabiduría divina y a las disposiciones de la naturaleza: un elemento del orden social, un supuesto necesario de las iniciativas humanas, un estímulo al trabajo en beneficio de los bienes temporales y trascendentes de la vida, y por tanto, de la libertad y de la dignidad del hombre, creado a imagen de Dios, que desde el principio le asignó para su utilidad un dominio sobre las cosas materiales" ${ }^{18}$. Por ello, la Iglesia considera que las razones de bien común que imponen la propiedad privada van mucho más allá de la mera conveniencia económica, y declara que no es la propiedad privada la que deba seguir el progreso técnico, sino que éste subordinarse a ella ${ }^{19}$, pues hay valores más altos comprometidos. Por ello "la conciencia cristiana no puede admitir como justo un ordenamiento social que, o niega en absoluto o hace prácticamente imposible o vano el derecho natural de propiedad, tanto sobre los bienes de consumo como sobre los medios de producción. $\mathrm{Ni}$ puede aceptar tampoco esos sistemas que reconocen el derecho de propiedad conforme a un concepto totalmente falso, y se hallan por consiguiente en pugna con el verdadero y sano orden social" 20 "Si las señales de los tiempos no engañan, en la segunda fase de las controversias sociales en que ya entramos, tienen preferencia (con relación a la cuestión operaria, que dominó la primera fase) otras cuestio nes y problemas. (...) Además, la protección del individuo y de la familia frente a la 
corriente que amenaza arrastrar a una socialización total, a cuyo fin se tornaría pavorosa realidad la imagen terrorífica del Leviatán. La Iglesia trabará esta lucha hasta el extremo, pues se trata aquí de valores supremos, la dignidad del hombre y la salvación del alma" 21 .

Así, el bien común supone el derecho de propiedad privada, y la autoridad no podrá nunca atentar contra tal derecho, pues "la sociedad civil ha sido instituida para garantizar el derecho natural y no para conculcarlo", y debe ser extremadamente prudente en materia de limitaciones al dominio, pues puede caer insensiblemente en el socialismo: "pero habrá de proceder siempre con toda cautela, no sea que viole los derechos de los ciudadanos o establezca, bajo apariencia de utilidad pública, algo que la razón no apruebe, ya que las leyes han de ser obedecidas sólo en cuanto estén conforme con la recta razón y con la ley eterna de Dios" 22 . Y Pio XII precisa el contenido del bien común en sus relaciones con el derecho natural, y más específicamente con el de "bienes materiales", lo que equivale a decir derecho a la propiedad: "Tutelar el campo intangible de los derechos de la persona humana y hacerle llevadero el cumplimiento de sus deberes, debe ser oficio esencial de todo Poder Público. ¿Acaso no lleva esto consigo el significado genuino del bien común, que el Estado está llamado a promover? De aquí nace que el cuidado de este bien común no lleva consigo un poder tan extenso sobre los miembros de la comunidad, que en virtud de él sea permitido a la autoridad pública disminuir el desenvolvimiento de la acción individual arriba mencionada, decidir directamente sobre el principio o (excluso el caso de legítima pena) sobre el término de la vida humana, determinar de propia iniciativa el modo de su movimiento físico, espiritual, religioso y moral en oposición con los deberes y derechos personales del hombre, y con tal intento abolir o quitar su eficacia al derecho natural de bienes materiales. Deducir extensión tan grande de poder del cuidado del bien común, significaría atropellar el sentido mismo del bien común y caer en el error de afirmar que el fin propio del hombre en la tierra es la sociedad; que la sociedad es fin de sí misma: que el hombre no tiene que esperar otra vida de la que se termina aquí abajo" 23.

Por otra parte, Pío XI precisa el significado del bien común de la sociedad civil, que es justamente un orden que posibilita a los individuos la consecución de sus propios fines, es decir, un bien de contenido esencialmente moral: "Ahora bien, este fin, es decir, el bien común de onden temporal consiste en una paz y seguridad de las cuales las familias y cada uno de los individuos puedan disfrutar en el ejercicio de sus derechos, y al mismo tiempo en la mayor abundancia de bienes espirituales y temporales gue an posibles en esta vida mortal mediante la concorde colaboración activa de todos los "jutadanos" 24.

León XIll, a su vez, nos expone el contenido del bien común diciendo: "Ahora bien, lo que más contribuye a la prosperidad de las nacicnes es la propiedad de las costumbres, la recta y ordenada constitución de las familias, la observancia de 
la religión y de la justicia, las moderadas cargas públicas y su equitativa distribución, los progresos de la industria y del comercio, la floreciente agricultura y otros factores de esta índole, si quedan, los cuales, cuanto con mayor afán son impulsados, tanto mejor y más felizmente permitirán vivir a los ciudadanos" 25.

Para obtener el orden, la paz y la seguridad jurídica, es de todo punto de vista necesaria la propiedad privada. Más adelante analizaremos con mayor detalle las relaciones entre el derecho de propiedad privada y el orden y la paz entre los hombres ${ }^{26}$. Por otra parte, toda seguridad jurídica descansa en él, pues si falta se cae a la órbita de lo precario, de lo que depende siempre del juicio de otro, de lo que, sin que medie voluntad del titular del derecho, hoy es y mañana puede no ser ${ }^{27}$. Por otra parte, el derecho es el objeto de la justicia, y ya hemos visto cómo la justicia no es concebible sin el derecho de propiedad privada 28.

Con respecto a las consecuencias de la supresión de la propiedad privada, León XIII nos traza el siguiente cuadro: "Pero, además de la injüsticia, se deja ver con demasiada claridad cuál sería la perturbación y el transtorno de todos los órdenes, cuán dura y odiosa la opresión de los ciudadanos que habría de seguirse. Se abriría de par en par la puerta a las mutuas envidias, a la maledicencia y a las discordias; quitado el estímulo al ingenio y a la habilidad de los individuos, necesariamente vendrian a secarse las mismas fuentes de las riquezas, y esa igualdad con que sueñan no sería ciertamente otra cosa que una general situación, por igual miserable y abyecta de todos los hombres sin excepción alguna. De todo lo cual se sigue claramente que debe rechazarse de plano esa fantasía del socialismo de reducir a común la propiedad privada, pues que daña a esos mismos a quienes se pretende socorrer, repugna a los derechos naturales de los individuos y perturba las funciones del Estado y la tranquilidad común" 2930 .

Pues "la política social y económica del porvenir, la actividad ordenadora del Estado, de los municipios, de las instituciones profesionales, no podrán conseguir de manera durable su alto fin con la verdadera fecundidad de la vida social y el normal rendimiento de la economía nacional, sino respetando y tutelando la función vital de la propiedad privada en su valor personal y social" 31 .

Respecto al bien común económico, el derecho de propiedad privada es igualmente necesario. Más adelante analizaremos la relación que existe entre dicho derecho y la diligencia en la gestión económica ${ }^{32}$. Por ahora nos contentaremos con citar algunos textos pontificios sobre el tema.

"Ya nuestro inmortal predecesor León XIII, en su célebre encíclica Rerum Novarum, enunció el principio de que, para todo recto orden económico y social, "debe ponerse como fundamento inconcuso el derecho de la propiedad privada" ${ }^{33}$. Además, Pío XII nos pone en guardia frente al peligro de que se sustituya la responsabilidad personal del empresario (individuo o sociedad) a formas anónimas colecti- 
vas: "Una mentalidad socialista se acomodaria fácilmente a semejante situación; sin embargo, ésta no dejaria de inquietar a quien conoce la importancia fundamental del derecho a la propiedad privada para favorecer las iniciativas y fijar las responsabilidades en materia de economia" ${ }^{34}$.

Pues, si mantiene y difunde la propiedad privada 35 "Habría, además, mayor abundancia de productos de la tierra. Los hombres, sabiendo que trabajan lo que es suyo, ponen mayor esmero y entusiasmo. Aprenden incluso a amar más la tierra cultivada por sus propias manos, de la que esperan, no sólo el sustento, sino también una cierta holgura económica para sí y para los suyos. No hay nadie que deje de ver lo mucho que importa este entusiasmo de la voluntad para la abundancia de productos y para el incremento de las riquezas de la sociedad" ${ }^{36}$.

Cabe hacer notar, además, que aún en el hipotético caso en que la supresión del derecho de propiedad privada trajera consigo beneficios económicos (hipótesis que sólo aceptamos argumentandi gratia, pues en el hecho no puede darse para la totalidad de una economía), como hay valores más altos comprometidos la propiedad debe ser respetada. La economía se ordena al último fin del hombre y a los bienes morales, y no éstos a aquélla: "Pues, aun cuando la economía y la disciplina moral, cada cual en su ámbito, tienen principios propios, a pesar de ello es erróneo que el orden económico y el moral estén tan distanciados y ajenos entre sí, que bajo ningún aspecto dependa aquél de éste. Las leyes llamadas económicas, fundadas sobre la naturaleza de las cosas y la índole del cuerpo y alma humanos, establecen, desde luego, con toda certeza qué fines no y cuáles sí, y con qué medios puede alcanzar la actividad humana dentro del orden económico. pero la razón también, apoyándose igualmente en la naturaleza de las cosas y del hombre, individual y socialmente considerado, demuestra claramente que a ese orden económico en su totalidad le ha sido prescrito un fin por Dios Creador" ${ }^{37}$.

\section{Otras condiciones del bien común:}

Dentro de la doctrina católica la estabilidad de la familia, el respeto al principio de subsidiaridad, la garantía de la libertad moral del hombre y la riqueza y continuidad de la sana tradición son considerados requisitos esenciales del bien común temporal.

Así, pues, el derecho de propiedad privada, incluso sobre los bienes produc. tivos, es condición esencial, impuesta por la misma naturaleza, para el bien común. "Ahora bien, la ley natural, es decir, la voluntad de Dios promulgada por medio de aquélla, exige que en la aplicación de las cosas naturales a los usos humanos se observe el recto orden, consistente en que cada cosa tenga gu dueño" 38 .

Los argumentos que aquí se han dado se refieren propiamente a la supre- 
sión del derecho de propiedad privada. Si sólo se lo mutila tales argumentos valen analógicamente en forma proporcional ${ }^{39}$.

\section{El principio de subsidiaridad}

Para estudiar las relaciones que existen entre el derecho de propiedad privada y el principio de subsidiaridad cumple fijar primeramente qué es y en qué consiste tal principio.

Ia formulación más acabada y precisa del principio de subsidiaridad se encuentra en la Encíclica Mater et Magistra de S.S. Juan XXIII, quien, tras puntualizar las formas de intervención del poder civil, ratifica la enseñanza de Pío XI sobre la materia: "Esta acción del Estado que fomenta, estimula, ordena, suple y completa está fundamentada en el principio de la función subsidiaria (Cf. Acta Apostólica Sedis 23 (1931) p. 203), formulado por Pío XI en la Encíclica Quadragesimo Anno: Sigue en pie en la filosofía social un gravísimo principio, inamovible e inmutable: así como no es lícito quitar a los individuos y traspasar a la comunidad lo que ellos pueden realizar con su propio esfuerzo e iniciativa, así tampoco es justo, porque daña y perturba gravemente el recto orden social, quitar a las comunidades menores e inferiores lo que ellas pueden realizar y ofrecer por sí mismas, y atribuirlo a una comunidad mayor y más elevada, ya que toda acción de la sociedad, en virtud de su propia naturaleza, debe prestar ayuda a los miembros del cuerpo social, pero nunca distribuirlos ni absorberlos" 40 . La formulación es clara y concisa, y no se requieren comentarios para comprender el principio enunciado.

Como antecedentes de tal formulación se pueden citar, principalnente, la Encíclica Rerum Novarum ${ }^{41}$, la Encíclica Divini Illius Magistri, que se ocupa especialmente de los derechos de la familia ${ }^{42}$ y el discurso La solemnitá ${ }^{43}$. En todos ellos se defiende, poniendo el acento en una u otra institución, el mismo principio, que ahora analizaremos en algunas de sus proyecciones más directas, para luego relacionarlo con el derecho de propiedad.

Cabe hacer notar, en primer lugar, que la subsidiaridad presenta al análisis dos vertientes o sentidos. En un sentido, se la entiende como una facultad de las sociedades superiores de intervenir en asuntos propios de las inferiores o de los individuos cuando lo exija una manifiesta y objetiva razón de bien común y las sociedades inferiores o los individuos no puedan satisfacerla. En este sentido, son antecedentes de la subsidiaridad todos los textos pontificios que propugnan la intervención de la autoridad para reprimir abusos y estimular u ordenar la actividad de sus subordina dos. Pero, en cuanto exista causa de bien común, esto no es sino una ratificación de un principio tradicionalmente sustentado por la filosofía social católica, que desmiente así una vez más al liberalismo 
La segunda vertiente es la razón de límite que reviste la subsidiaridad. El Estado puede, si el bien común lo exige, intervenir en materias de la competencia de sociedades inferiores o de individuos, pero sólo en la medida indispensable para obtener el fin perseguido, procurando que su acción sea lo menos lesiva posible a los intereses y a los fueros propios de las sociedades subordinadas o de los individuos. Así, en la consecución del bien común las sociedades superiores sólo deben actuar en subsidio de las inferiores. Se concibe así el cuerpo social no como una mera agrupación amorfa de individuos-masa dependientes de un poder centralizado, que es la concepción común al liberalismo y al marxismo -aunque discrepen en la extensión que deba tener ese poder centralizado-, sino como el producto de la estructuración y organización progresiva de los individuos en sociedades menores -de las cuales la más natural y principal es la familia- y de éstas en sociedades superiores. Resulta así una organización funcional cuya vitalidad surge de abajo hacia arriba y en la que los individuos o sociedades menores no son absorbidos sino perfeccionados. El sistema completo descansa en la idea de respetar la vida y plenitud de los miembros componentes para mantener la vida del todo. Así, el individuo debe tener en su mano todas las atribuciones necesarias para ser el primer responsable de su propio destino y alcanzar su fin ${ }^{44}$; la familia debe gozar de todas las facilidades y medios para su subsistencia y desarrollo propios ${ }^{45}$, y así, sucesivamente los gremios, municipios;, universidades, regiones y demás corporaciones, Se establece, además, una jeraruguía entre los fines de los miembros, siendo el fin de los superiores facilitar la consecución de los fines de los inferiores en sus respectivas esferas, rematando todos en su fin común, en su bien común, que es facilitar la vida, el perfeccionamiento y la salvación del hombre. Todas estas sociedades, como seres accidentales que son, reciben el ser de una determinación accidental de los hombres que las componen, pues ellos son los seres sustanciales que les posibilitan la existencia. Así, la vida de una sociedad arranca de la vida de sus miembros y es proporcional a ella en actividad y riqueza. A su vez, la vida, riqueza, actividad y acción de una sociedad superior emanan de la de las sociedades inferiores que la componen.

De este modo, para cumplir su fin y para crecer y perfeccionarse ellas mismas, las sociedades superiores deben respetar escrupulosamente los derechos de las inferiores, y estimular su vida y acción. Un conjunto humano así estructurado es lo que propiamente se llama un pueblo, como lo dice S.S. Pio XII: "Pueblo y multitud amorfa, o, como suele decirse, "masa", son dos conceptos diferentes. Fl pueblo vive y se mueve por su vida propia; la masa es de por sí inerte y sólo puede ser movida desde fuera. El pueblo vive de la plenitud de la vida de los hombres que lo componen, cada uno de los cuales -en su propio puesto y según su manera propia- es una persona consciente de su propia responsabilidad y de sus propias convicciones. La masa, por el contrario, espera el impulso del ex terior, fácil juguete en manos de cualquiera que explote sus instintos o sus impresiones, presta a seguir sucesivamente hoy 
esta bandera, mañana otra distinta. De la exuberancia de vida propia de un verdadero pueblo se difunde la vida, abundante, rica, por el Estado y por todos los organismos de éste, infundiéndoles, con un vigor renovado sin cesar, la conciencia de su propia responsabilidad, el sentido verdadero del bien común. El Estado, por el contrario, puede servirse también de la fuerza elemental de la masa, manejada y aprovechada con habilidad: en las manos ambiciosas de uno sólo o de muchos, reagrupados artificialmente por tendencias egoistas, el Estado mismo puede, con el apoyo de la masa, reducida a simple máquina, imponer su capricho a la parte mejor del verdadero pueblo; el interés común queda así gravemente lesionado por largo tiempo, y la herida es con frecuencia muy difícil de curar" ${ }^{46}$.

Luego, para la vida de un pueblo, el principio de subsidiaridad es condición esencial, ya que, en último análisis, no es sino una consecuencia del respeto a la dignidad de persona libre del hombre, pues es a ella a quien en definitiva se honra al respetar sus consecuencias, como son todas las sociedades intermedias. Así lo recuerda Pío XII, al decir: "Pero convertir la estatización en una regla normal de la organización pública sería tratornar el orden de las cosas. La misión del derecho público es, en efecto, servir el derecho privado pero no absorberlo. La economía -por lo demás, como las restantes ramas de la actividad humana - no es por su naturaleza una institución del Estado; por el contrario, es el producto viviente de la libre iniciativa de los individuos y de sus agrupaciones libremente constituidas" 47.

Y en otro tex to insiste: “ ¿Cuál es ... la verdadera noción del Estado, sino la de un organismo moral fundado sobre el orden moral del mundo? Su función, su magnifica función, por el contrario, es favorecer, auxiliar, promover la íntima alianza, la cooperación activa en el sentido de una más elevada unidad de los miembros que, al mismo tiempo que respetan su subordinación al fin del Estado, promueven del mejor modo el bien de la comunidad, precisamente en la medida en que conservan y desenvuelven su carácter particular y general. Ni el individuo ni la familia deben ser absorbidos por el Estado. Cada uno conserva y debe conservar la propia libertad de movimientos, mientras no promueva el riesgo de causar perjuicio al bien común. Además, hay ciertos derechos y libertades de los individuos -de cada individuo- o de la familia, que el Estado debe proteger siempre y no puede violar ni sacrificar a un pretendido bien común. Nos referimos, para no citar más que algunos ejemplos, al derecho a la honra y a la buena reputación, al derecho y a la libertad de venerar al verdadero Dios, al derecho originario de los padres sobre los hijos y sobre su educación" 48 .

Asi, la subsidiaridad no es mera regla de eficiencia técnica o productiva, es un principio jurídico, que emana de la realidad misma de las cosas. Ello es recalcado por Juan XXIII con decisión al decir: "in philosophiae sociali gravissimun illud principium quod neque movere neque mutare potest" 49 . Queda así claro el carácter inmutable e inviolable del principio de subsidiaridad, como principio de derecho na- 
tural que es, en cuanto se deriva de la propla naturateza ae sas socueuaues, y en uıtmo término, de la propia naturaleza del hombre. Este principio entronca en su base con el hilemorfismo aristotélico-tomista y con la teoría de las causas, en cuanto circunscribe los efectos - en este caso la acción de la sociedad superior- a los límites fijados por su causa justificativa, constituida en este caso por la razón de bien común.

Es además conforme con la naturaleza de las sociedades, pues éstas reciben de sus miembros el ser para conseguir el bien de éstos en ura esfera en que cada uno por separado no lo conseguiría. Este bien perseguido por todos es el bien común, fin de la sociedad. Así, de sociedad en sociedad, encontraremos en la base siempre al hombre, ser sustancial que les posibilita la existencia. Las sociedades existen en los hombres a modo de determinaciones accidentales, realizadas con vistas al bien común. Luego, si una sociedad se extralimita en sus funciones y va más allá de lo que exige el bien común, cae en el no ser. Traspuesto tal límite la sociedad no existe, no tiene entidad, por lo que su acto carece de toda validez jurídica. Con lo que hemos, de paso, encontrado la raíz ontológica del concepto de competencia ${ }^{50}$.

\section{Subsidiaridad y propiedad}

Conforme a lo visto, el principio de subsidiaridad manda que se respete, en las sociedades inferiores y en los individuos, el ejercicio de los derechos que les posibiliten ser los primeros responsables de sí mismos. Ahora, para que un individuo, una familia y otra sociedad, sean los primeros responsables de sí mismos, es de todo punto indispensable, el derecho de propiedad, por varias razones:

10 El principio de subsidiaridad manda respetar toda la órbita de derechos compatibles con el bien común y necesarios para el cumplimiento del fin de las $80-$ ciedades y de los individuos, y el derecho de propiedad es un derecho natural del hombre y de la familia, y condición normal necesaria para cumplir su fin, en cuanto a su subsistencia, a su libertad y a su perfeccionamiento. En cuanto a la familia, es además condición de su estabilidad y substrato precioso de la tradición.

$20 \quad$ El principio de subsidiaridad y el derecho natural de libre iniciativa están recíprocamente adecuados, más aún, son como dos aspectos de una misma realidad, y el derecho de propiedad privada individual es condición necesaria de la libre iniciativa, como está muy bien puntualizado en Mater et Magistra: "Por otra parte, en vano se reconocería al individuo el derecho de actuar con libertad en el campo económico si no le fuese dada al mismo tiempo la facultad de elegir y emplear libremente las cosas indispensables para el ejercicio de dicho derecho ${ }^{51}$. De donde se dededuce que la subsidiaridad pierde razón de ser si no se reconoce la propiedad privada individual, lo que significa que tal derecho es condición esencial del principio que analizamos. $Y$ si la subsidiaridad es inmutable e inviolable, también debe serto su condición esencial, lo que nos proporciona un nuevo argumento en favor del derecho de propiedad privada individual como preceptuado por la ley natural. 


\section{Subsidiaridad y limitaciones al dominio}

En materia de limitaciones al dominio la subsidiaridad impone mantenerse rigurosamente dentro de los límites fijados por la causa justificativa de la acción de la sociedad superior, eligiendo siempre la vía menos lesiva ${ }^{52}$. Así por ejemplo, ante la necesidad de incrementar la producción agrícola se debe facilitar el crédito, la comercialización y demás funciones conexas. Si ello fuere insuficiente se podrá aplicar una política de estímulos tributarios; si tampoco basta, se podrá, si la situación es muy grave, imponer un arrendamiento temporal, y sólo agotadas todas las otras medidas posibles resultaría lícito recurrir a la expropiación ${ }^{53}$, y no de una manera general, sino sólo en los casos en que haya concretamente una objetiva y manifiesta ne cesidad de bien común.

Por ello, en el pensamiento de los Papas, el totalitarismo invasor aparece como una tentación para el Estado, opuesta al deber de obediencia al principio de subsidiaridad: "La fidelidad de los gobernantes a este ideal (de proteger la libertad del ciudadano y servir al bien común) será, además, su mejor salvaguardia contra la doble tentación que los acecha, ante la amplitud creciente de su tarea: tentación de flaqueza, que los haría abdicar bajo la presión conjugada de los hombres y de los acontecimientos; tentación inversa de estatismo, por la cual los poderes públicos se substituirian indebidamente a las libres iniciativas privadas para regir, de manera inmediata, la economía social y otros ramos de la actividad humana. Ahora bien, si hoy no se puede negar al Estado un derecho que le recusaba el liberalismo, no es menos verdad que su tarea no es, en principio, asumir directamente las funciones económicas, culturales y sociales, que dependen de otras competencias; su cometido por el contrario, consiste en asegurar la real independencia de su autoridad, de ma nera que puede conceder a todo lo que representa un poder efectivo y valioso en el país, una parte justa de responsabilidad, sin peligro para su propia misión, de coordenar y orientar todos los esfuerzos para un fin común superior" ${ }^{44}$. Así, el Estado debe favorecer la propiedad individual y la libre iniciativa. Sólo podrá actuar sobre ellas para fomentar, estimular, ordenar, suplir y complementar (fovet, excitat, ordinat, supplet atque complet) ${ }^{55}$, dando siempre la máxima libertad de acción posible a las personas y sociedades inferiores, pues: "Es preeiso, en la organización de la producción, asegurar todo su valor directivo a este principio, siempre defendido por la enseh anza social de la Iglesia: que las actividades y los servicios de la sociedad deben tener un carácter "subsidiario"; solamente ayudar o completar la actividad del individuo, de la familia o de la "profesion" 56.

Pues, "la economía debe ser obra. ante todo, de la iniciativa privada de los individuos, ya actúen éstos por si solos, ya se asocien entre sí de múltiples maneras para procurar sus intereses comunes" 57 . 
Resumiendo, el principio de subsidiaridad está exigido por la natuıaleza misma de las cosas, y el derecho de propiedad es simultáneamente corolario y condición esencial de él.

\author{
1 S.C.G. $3,17$. \\ 2 SANTIAgo RamiRez O.P., La doctrina Política de Santo Tomás, Instituto Social \\ León XIII, Madrid, p. 29.

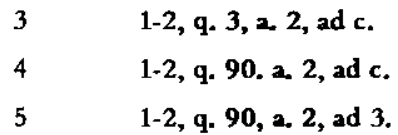 \\ 6 P. CARLOS SORIA O.P., Introducción a la cuestión 90 de la I-II de la Suma teológi- \\ ca de Santo Tomás de Aquino, ed. cit., tomo VI, p. 23. Hemos seguido de cerca a este autor. \\ 7 Ibid, p. 24-25. \\ 8 Pío XI, QA, 43, DS págs. 712-713. \\ 9 RN, 9, DS págs. 319-320.
}

10 PLINIO CORREA DE OLIVEIRA, La libertad de la Iglesia en el Estado Comunista, pág. 12, ed. del Instituto de Investigaciones Universitarias "San Pío X", Stgo, de Chile, Cla ret, 1965. Esta obra ha sido recomendada por la Sagrada Congregación de Seminarios y Universidades, considerándola: "eco fidelísimo de los Documentos del Supremo Magisterio de la Iglesia, inclusive las huminosas encíclicas Mater et Magistra de Juan XXIII y Ecclesiam Suam de Paulo VI, felizmente reinante".

11 Ibid.

12 Ibid. págs 13-14.

13 Vid. ỉbid. págs. 14-15.

14 Benedicto XV, Carta al Obispo de Bérgamo, de 11 de marzo de 1920, DS p. 525.

15 Vid. Santo Tomás de Aquino, De regimine Principum, I, cap. 14 y 15.

16 Vid. RN, DS p. 337.

17 Pío XII, disc. La solemnitá, de $1^{\circ}$ de junio de 1941, 5, DS p. 954.

18 Pío XII, Mens, radiof. de $1^{\circ}$ de septiembre de 1944, 28, DS p. 984 . En cuanto parte de la ley natural el derecho de propiedad privada es un requisito esencial de todas las formas agibles de bien común en todas las sociedades. Respecto a la sociedad política constituye un requisito esencial de su bien específico, pues no cabe concebir la virtud practicada en común con violación de la ley natural. Esta consecuencia moral de la violación del derecho de propiedad es la más grave pero no la única, pues por la íntima trabazón estructural de los distintoselementos y propiedades en la unidad del ser, la violación de la ley natural deteriora todos los contenidos subordinados y concretos del bien común, no sólo en cuanto a su valor y finalidad, al privar de sentido a la referencia que los justificaba, sino incluso en cuanto a su eficacia en el cumplimien. to de sus objetivos inmediztos, como se puede apreciar respecto de la producción económica o de la garantía de la libertad. 
lbid. 31 .

20 Pío XII, ob. cit. 22 y 23, DS p. 983.

21 Pío XII, Radiomensaje al "Katholikentag" de Viena, de 14 de septiembre de 1952, "Discorsi e Radiomessaggi", vol. XIV, p. 314.

22 RN, DS p. 350. Si bien esta cita se refiere a las limitaciones al derecho de asociación, nos parece aplicable, analógicamente, a todos los derechos naturales.

23 Pío XII, Disc. La solemnitá, de $1^{\circ}$ de junio de 1941 , en el $50^{\circ}$ Aniversario de la Rerum Novarum, 15, DS p. 957.

24 Pío XI, Enc. Divini Illius Magistri, 36 DP p. 545.

25 RN, DS p. 335.

26 En otra ocasión volveremos sobre el tema.

27 Ibid.

28 Vid. cita 11.

29 RN, 11 DS p. 321.

30 "Para solucionar este mal, los socialistas, atizando el odio de los indigentes contra los ricos, tratan de acabar con la propiedad privada de los bienes, estimando mejor que, en su lugar, todos los bienes se an comunes y administrados por las personas que rigen el municipio o gobiernan la nación. Creen que con este traslado de los bienes de los particulares a la comunidad, distribuyendo por igual las riquezas y el bienestar entre todos los ciudadanos, se podría curar el mal presente. Pero esta medida es tan inadecuada para resolver la contienda, que incluso llega a perjudicar a las propias clases obreras; y es, además, sumamente injusta, pues ejerce violencia contra los legítimos poseedores, altera la misión de la república y agita fundamentalmente a las naciones" (RN, 2, DS págs. 312-313).

31 Pío XII, Mens. radiof. de $1^{\circ}$ de septiembre de 1944, 30, DS págs. 984-985.

32 Vid, nota 26.

33 Pío XII, ob. cit., DS p. 983.

34 Pío XII, Aloc. al Congreso Internacional de Estudios Sociales, de 3 de junio de 1950 , DS p. 1094.

35 Difund ir el derecho de propiedad supone respetar su inviolabilidad.

36 RN, DS p. 347.

37 QA, 42, DS p. 712.

$38 \quad$ lbid., 53, DS p. 718.

39 Vid. Pio XII, Disc. de 20 de mayo de 1948, DJ págs. 269-270.

40 MM, 53 CMM p. 22. Los hombres son materia remota y sustancial de todas las sociedades. En las que se vinculan inmediatamente a ellos en razón de sus fines (familia), son también materia próxima. Cada sociedad subsiste mientras subsistan sus causalidades, por lo que la familia, por ejemplo, en cuanto institución, no podrá dejar de existir mientras existan hombres. Por la subordinación de los fines respectivos, las que persiguen fines menos inmediatos se vinculan al ser substancial en que existen al través de las que persiguen fines más inmediatos, informando a su vez a éstas. 
Así tenemos, en forma esquemática, que la familia tiene por materia próxima a los hombres, que la constituyen, asumiéndolos en una nueva forma que los determina accidentalmente. El municipio tiene como materia remota a los hombres y como materia próxima a las familias, organizadas en una nueva forma que les permite cumplir más perfectamente sus fines, y así sucesivamente. Las sociedades más próximamente vinculadas al ser substancial tienen prioridad ontológica, y por ello de finalidad, respecto a las remotas, que están para perfeccionarlas y hacer posible el cumplimiento de sus fines.

DS, p. 311-360.

42

DS p. 527-577.

43

Pío XII, DS p. 952-962.

44

"Porque el ciudadano tiene siempre el derecho de ser el autor principal de su progreso propio" (Juan XXIII, MM, 151. CMM p. 64).

45 "Lo mismo a los individuos que a las familias debe permitírseles una justa libertad de acción, pero quedando siempre a salvo el bien común y sin que se produzca injuria para nadie". (Pío XI, QA, DS p. 703).

46 Pío XII, Mens, radiof. de Navidad de 1944, Discorsi e Radiomessaggi, vol. VI, p. 328-329.

47 Pío XII, Disc. de 7 de mayo de 1944, a la IX Conferencia de la Unión Internacional de las Asociaciones Patronales Católicas, Discorsi e Radiomessaggi, vol, XI, p. 63.

48 Pío XII, Disc. al Congreso Internacional de Ciencias Administrativas, de 5 de agosto de 1950. Discorsi e Radiomessaggi, vol. XII, p. 160.

49

MM No 53, CMM, p. 22.

50 La competencia sería así el cauce o ámbito de acción jurídica de la sociedad, el principio que ordenaría sus movimientos del terminus a quo al terminus ad quem. Coincide así con el concepto de ley. En definitiva la ley de la sociedad se traduce en competencia.

Las atribuciones jurídicas concretas serán determinadas por la naturaleza misma de la sociedad, y, en consecuencia, por el fin de ésta. En las sociedades naturales tales atribuciones están determinadas directamente por la naturaleza humana. Las sociedades de derecho positivo las encuentran en el acto voluntario de sus componentes o en la ley dada por autoridad que determine el fin y los medios a él conducentes.

$\mathrm{Y}$ entre ambos extremos, toda la gam a de gradaciones y combinaciones pensables.

$51 \quad$ MM 109.

52 Vid, nota 26.

53 "El Estado puede, en el interés común, intervenir para reglamentar su uso (de la propiedad) o incluso, si no puede proceder equitativamente de otro modo, decretar la expropiación, dando la indemnización conveniente". (Pío XII Mens. radiof. de 10 de septiembre de 1944, DS pág. 985).

54 Pío XII, carta de 14 de julio de 1954, a la $41^{\text {a }}$ Semana Social de Francia. Discorsi e Radiomessaggi, vol. XVI, págs. 465-466.

55 MM 53.

56 Pío XII, Carta a Carlos Flory, presidente de las Semanas Sociales Francesas, de 18 de julio de 1947, DS, pág. 1034.

57 MM 51. 
